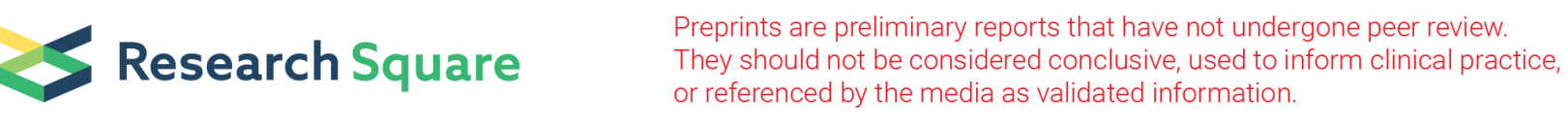

\title{
Factors associated with knowledge on risk factors of sexual abuse among house girls and house boys in Singida Municipality, Central zone Tanzania: A cross- sectional study
}

Filmon Emily ( $\nabla$ filmonemily@gmail.com )

University of Dodoma https://orcid.org/0000-0001-9484-5554

Dedius E. Peter

University of Dodoma

Walter C. Milanzi

University of Dodoma

Angelina A. Joho

University of Dodoma

Fabiola Moshi

University of Dodoma

\section{Research Article}

Keywords: House boys, house girls, sexual abuse, Singida municipality

Posted Date: April 15th, 2021

DOI: https://doi.org/10.21203/rs.3.rs-410346/v2

License: (c) (i) This work is licensed under a Creative Commons Attribution 4.0 International License. Read Full License 


\section{Abstract}

Background: Sexual abuse is a situation whereby any people or individual entered in any sexual malpractice or sexual contact without his/her will. Sexual abuse among house girls and house boys is among of general medical issue in our nation particularly in the urban areas and towns. The aim of the study was to examine predicators associated with knowledge on risk factors of sexual abuse among house girls and house boys in Singida Municipality.

Methods: The cross section study involved a total of 252 participants from the selected house hold in Singida Municipality. A multistage sampling technique was used to obtain sample and data was collected by using selfadministered structured questionnaire. Chi-square and logistic regression were used to determine the association between knowledge on risk factors and sexual abuse among house girls and house boys.

Results: The large numbers of respondents with mean age of 22years old were single. Only $53.1 \%$ of house girls were knowledgeable on risk factors associated with sexual abuse compared to house boys. After control of the confounders the predictors of knowledge about risk factors on sexual abuse were educational level $(A O R=0.332, p=$ $0.002,95 \% \mathrm{Cl}: 0.167 ; 0.659)$, how did you find a job(AOR=2.412, $\mathrm{p}=0.001,95 \% \mathrm{Cl}: 1.433 ; 2.523)$, and type of family he/she living(AOR=4.672, $p=0.002,95 \% \mathrm{Cl}: 0.0709 ; 0.719$, nuclear family $(A O R=4.023, p=0.023,95 \% C l: 0.101 ; 0902)$.

Conclusion: The findings depicted that the study participants have inadequate knowledge on risk factors associated with sexual abuse and it discovered that the influencing factors were education level, means of getting a job and type of family.

\section{Background}

Wisconsin Child welfare pds Reporter Training defined Sexual abuse as when any people or individual entered in any sexual malpractice or sexual contact without his/her will (1). Forms of brutality (abuse) that including pertaining in sexual intercourse with kids, girls or boy (by questioning or providing something or by any means), intend to expose (of the private parts, house girl's sexual exploitation) or using these house keepers to increase sexuality such as watching sexual movies.

Assault and other types of sexual conducts direct against house workers happen in variety of settings, in their homes, the home environment and around the city. 1 of every 3 girls and 1 out of 4 boys experience sexual contact in whole life (2). Lastly not list 1 out of 5 girls and 1 in every 38 boys has in contact with fully or doing sexual acts and 1 in every 14 boys were made to penetrate somebody the whole of his/her life duration. In age of 11-17 years, 1 of every 3 girls had raped and 1 out of 8 reported this incidence. Mostly 1 out of 5 girls (18.3\%) and 1 in every 71 boys (1.4\%) in the USA has been raped some occasion in their lifetime (3).

Furthermore, WHO revealed sexual assaults and the precipitating factors that increases sexual abuse in the families were male-female inequalities views, multiple partners/infidelity, acceptance of violence, low level of education, gang membership and harmful or use of alcohols or drug (4). Various plans and approaches have been made by world association to varnish sexual abuse in the society, education institutions, families and characters of the people. These techniques and plans such as motivation in social conducts and norms that shield against brutality, teaching ability to end sexual brutality by providing chance to empower and uplift these women, young ladies, men and young boys by creating protective environments and defense house workers/survivors to decrease endangerment to them (2). 
Few studies were done and reported on sexual brutality on these house workers. Moreover, in African countries has revealed that there are increase in sexual assaults problem that still exist such as in Namibia it accounts $3.6 \%$ and South Africa 14.3\%(4). In Uganda is estimated to be 23\%, Zambia 23\%, Ghana 30\%, Malawi 38\% in the same way they tried to report sexual abuses in children, women, boys and men in the societies (5). According to WHO report on sexual violence and sexual assaults among children, it was observed that most young women experience sexual assaults while are in educational organizations as revealed by the research done in Meru Kenya(4).

African countries are still facing the same problem because findings from different countries about sexual abuse on children and women especially in primary schools show that different sexual acts were performed including touching their genital parts, and even raping the students in primary schools (4). As reported by pan African medical journal that 311 children experienced rape or assault due to different influential factors such as being teenager, disable people, low economic status, family structure, poor parenting, conflict within the family, being female, communication system and government organizations to be weak (6). They explained the effects of sexual abuse on the children and women and ways to minimize the situations in the societies and families through counseling, supporting them, and psychological rehabilitation (6).

The United Nations for children's fund in 2016 tried to show different facilitating factors that increase the occurrence of sexual assaults in African countries such as being female gender, poor relationship within the family, meandering children, poor economic status of the family and performing of children's activities which are illegal such as house workers (5). Despite the studies which were done on sexual assaults in Africans countries on men, young children but were little research done sexual assaults among house workers (house girls and house boys).

Different research which were done in the Republic of Tanzania have portrayed the different circumstances of sexual assaults on women, adult women and men, children in different regions but no study which was done in Singida municipality on sexual abuse among house workers. Only one research was done on sexual assaults on students at school who at risks to be conducted sexual abuse due to the distance from school (4).

Moreover, the report from DIT findings show that $27.7 \%$ of young girls ranged $13-24 y e a r s$ old experience more sexual assaults than young boys of the same age which is $15 \%$ (6). No research were done on portraying sexual abuse among house girls and house boys in Singida region and the relationship of knowledge on risk factors and sexual assaults among house workers in Singida municipal and region in general. Therefore, the aim of this study was to examine predicators associated with knowledge on risk factors of sexual abuse among house girls and house boys in Singida Municipality.

\section{Methods}

\section{Study design and setting}

A descriptive cross-sectional study was conducted in Singida municipality since June 16, 2019 up to January 31, 2020, whereby the expected numbers of house girls and house boys were selected from almost six wards of Singida municipal found central highlands of Tanzania. The district had a total population of 150379 (73484 males, 76895 females) according to the census of August 26, 2012, population area $721 \mathrm{~km}^{2}$ and density of $208.7 \mathrm{~km}^{2}$. The mean age of house girls and house boys at Singida municipal was 22years old from the age ranged from 10 up to 34 years old.

\section{Study population}


The study population was 252 house girls and house boys who were living in Singida municipality.

\section{Data collection tools}

A pre-tested and structured self-administered questionnaire was used for data collection. It was adopted and modified and suited to address the objectives of this study. It was written in English version and then translated to Swahili version and retranslated to English to checkout for its consistency by the linguistics. The questionnaire was pretested to 50 house girls and house boys among 252 households. They were put into separate rooms to provide confidentiality and secrecy during the filling action of questionnaires by a researcher. Findings from the pre-test were applied to cross check the tool in terms of rectifying the queries in order to avoid some errors. This questionnaire was composed to get facts on the demographic data and associated elements on risk factors of sexual abuse among house girls and house boys. The factors with $p$-value of $\leq 0.05$ were considered to be predicators of being risk factors on sexual abuse.

\section{Sample size and sampling techniques}

The sample size was calculated by using Cochron formula as shown; $n=Z^{2} \times P(1-P) / e^{2}$, whereby; $95 \% C l(Z)=1.96$ and marginal error $=5 \%$ Proportion of other study $=50 \%$ or 0.5 Sample sized (NO). After adopting from Cochran formula (1963), $\mathrm{N}=\mathrm{NO} /(1+(\mathrm{NO}-1)) / \mathrm{Ns}$, Where; $\mathrm{N}=$ desired sample size, $\mathrm{NO}=$ Calculated sample size, $\mathrm{Ns}=$ Estimate of population. Hence $10 \%$ of the non-involving people were added so as to have my desired sample size which was equal to $113+13=126$. As a result of 126 girls and 126 boys, therefore the total target of the participants was 252.

Singida region was purposively selected to be the area understudy in Tanzania. One district (Singida urban) was selected by simple random sampling from the seven districts of Singida Region. Three staged multi-stage cluster sampling technique was used to obtain study participants. In first stage random sampling, all wards (16 wards) in Singida urban (municipality) were listed and by the use of purposive random sampling five wards (Ipembe, Mandewa, Uhamaka, Misuna and Mtipa) were picked. 20 streets were conveniently selected whereby 252 participants were obtained. The house workers with age ranged from 10 up to 34years were conveniently selected to be included into the sample.

\section{Data processing and analysis}

Data were collected from the respondents; both manual and software screening were done by using SPSS Version 20 to ensure the completeness and correctness of the data coded by SPSS. Descriptive statistics were done to obtain

frequencies and cross tabulation were used to describe relationship between risk factors. Both binary and multivariate logistic regression was used to show the association among the risk factors and sexual abuse.

\section{Results}

\section{Social-demographic characteristics}

The total 249 house workers (boys and girls) in Singida municipal involved in answering the questionnaire during data collection. The huge number $(67.1 \%, n=167)$ of the informants were girls and $(32.9 \%, n=82)$ were boys which contained a total of $100 \%$ of the respondents. Those respondents who were in the age group of 10 to 18 years old, with the mean age of 14 years old were $(160, n=64.3 \%)$. However, the huge numbers of informants abused were single which was equal to $89.2 \%$ of the participants quite different to other marital status of the informants. In terms 
of education levels, about half $(52.6 \%, n=131)$ of the respondents had completed primary education, $25.3 \%(n=63)$ had never gone to school and $22.1 \%(n=55)$ had completed secondary education and above. Other information is shown in table1.

Table: 1 Social-Demographic data of the informants $(n=249)$ 
Age

10 to $18 y r s$

64.3

19 to $25 y r s$

69

27.7

26 to $34 \mathrm{yrs}$

Sex

Male

Female

167

67.1

Education level

Never gone to school

Primary

Secondary and above

\section{Marital status}

Single

Married

Widow/widower

6

2.4

Divorce

\section{Living of the parent}

Yes

No

Type of family

Extended family

Nuclear family

Single parent family

Factors influencing he/she to find a job

Low standard of living

$\mathrm{He} / \mathrm{she}$ like that kind of job

None

How did you find a job

Someone found it for me

I found it myself

\section{Somebody sharing a sleeping room}

Alone

Children of the boss 
Heard information about sexual abuse among house girls and house boys

Yes

No

If they alive

Both are living

68(47.9)

$74(52.1)$

Only father is living

Only mother is living

$20(53.1)$

15(46.9)

Factors influencing knowledge on risk factors about sexual abuse among house girls and house boys in Singida municipal, Tanzania

Knowledge on risk factors were dichotomized to create two groups namely, those with adequate knowledge on risk factors and those with inadequate knowledge on risk factors. Out of 249 participants $50.2 \%$ of them had adequate knowledge about risk factors on sexual abuse among house girls and house boys. Knowledge on risk factors were significant associated with education level $\left(X^{2}=11.877, p=0.003\right)$, type of family where he/she living $\left(X^{2}=9.9179, p\right.$ $=0.007)$, how did you find a job $\left(X^{2}=10.949, p=0.001\right)$, and other factors influenced $\left(X^{2}=13.165, p=0.001\right)$.

Among 249 respondents whose age ranged between the age of 10 to 34years old, single 4(50\%) had adequate knowledge, married 109(49.3\%) had adequate knowledge, widow/widower 4(66.7\%) had adequate knowledge and divorced which is equal to $7(53.8 \%)$ had adequate knowledge on risk factors $\left(X^{2}=0.784, p=0.853\right)$. Moreover, other demographic data are depicted in the table 2.

Table 2: Relationship of the demographic data and knowledge level among the house girls and house boys $(n=249)$ 


\begin{tabular}{ccccc}
\hline Adequate & Inadequate & $\mathrm{X}^{2}$ & value \\
knowledge (\%) & knowledge (\%)
\end{tabular}$\quad$

\section{Age category}

10 to $18 y r s$

19 to $25 y r s$

26 to $34 y r s$

Sex

Male

Female

Education category

Never gone to school

Primary

Secondary and above

\section{Marital status}

Single

Married

Widow/widower

Divorce

\section{Living of the parent}

Yes

$$
\text { No }
$$

Type of family

Extended family

Nuclear family

Single parent family

Factors influencing he/she to find a job

Low standard of living

$\mathrm{He} /$ she like that kind of job

None

$\begin{array}{cc}78(49.1) & 81(50.9) \\ 40(52.2) & 33(47.8) \\ 10(50) & 10(50)\end{array}$

95(51.1)

50(48.9)

0.337

0.562

33(46.9)

34(53.1)

25(39.7)

$38(60.3)$

11.877

0.003

$79(60.3)$

$52(39.7)$

24(37)

34(63)

4(50)

4(50)

0.784

0.853

109(49.3)

112(50.7)

7(66.7)

2(33.3)

8(53.8)

6(46.2)

99(50.5)

29(48.1)

97(49.5)

0.097

0.775

27(51.9)

63(56.2)

56(50)

49(43.8)

9.917

0.007

9(20.8) 56(50)

19(79.2)

51(42.5)

13.165

0.001

$\begin{array}{ll}19(69.6) & 8(30.4) \\ 39(37.1) & 66(62.9)\end{array}$

How did you find a job

Someone found it for me 
Somebody sharing a sleeping room

Alone

Children of the

Boss

With boss

\author{
91(51.1)
}

$34(47.1)$

0(0)
$87(48.9)$

40(52.9)
0.318

0.578

Heard information about sexual abuse among house girls and house boys

Yes

No
115(51.6)
108(48.4)
2.180
9(36)
20(64)
0.140

If they alive

Both are living

68(47.9)

74(52.1)

1.743

0.418

Only father is living

17(61.5)

10(38.5)

Only mother is living

\section{Logistic regression showing association between risk factors and sexual abuse}

After control of other factors the predictors which were statistically significant were shown as follows; the first predictors was educational level as house girls and house boys who had primary level of education $(O R=2.839$, $\mathrm{p}=0.009,95 \% \mathrm{Cl}: 0.520 ; 1354$ and $\mathrm{AOR}=1.862, \mathrm{p}=0.002,95 \% \mathrm{Cl}: 0.167 ; 0659)$ had more chance of having adequate knowledge on risk factors on sexual abuse compared to those who had never gone to school and who had secondary education and above.

The second predictor was how did you find a job as house girls and house boys those who employed by finding a job by someone else ( $O R=2.352, p=0.001,95 \% \mathrm{Cl}: 1.412 ; 3.918$ and $A O R=2.412, p=0.001,95 \% \mathrm{Cl}: 1.433 ; 2.523)$ had more chance of being knowledgeable compared to house girl or house boy who found a job by herself or himself.

The last predictor was type of family where he/she was living as findings shown that in extended type of family $(\mathrm{OR}=4.421, \mathrm{p}=0.007,95 \% \mathrm{Cl}: 1.514 ; 12.913$ and $\mathrm{AOR}=4.672, \mathrm{p}=0.002,95 \% \mathrm{Cl}: 0.0709 ; 0.719)$ had more a chance of having adequate knowledge on risk factors about sexual abuse compared to those living in nuclear and single parent family.

Table 3: Association between education level (knowledge level) and type of family leading to sexual abuse 


\begin{tabular}{|c|c|c|c|c|c|c|c|c|}
\hline \multirow[t]{2}{*}{ Variable } & \multirow[t]{2}{*}{ OR } & \multirow[t]{2}{*}{ P-value } & \multicolumn{2}{|c|}{$95 \% \mathrm{CI}$} & \multirow[t]{2}{*}{ AOR } & \multirow[t]{2}{*}{ P-value } & \multicolumn{2}{|c|}{$95 \% \mathrm{CI}$} \\
\hline & & & Lower & Upper & & & Lower & Upper \\
\hline \multicolumn{9}{|l|}{ Education level } \\
\hline $\begin{array}{l}\text { Never } \\
\text { gone to } \\
\text { school }\end{array}$ & 1.780 & 0.0278 & 0.447 & 1.359 & 1.762 & 0.7016 & 0.433 & 1.889 \\
\hline \multicolumn{9}{|l|}{$\begin{array}{l}\text { Primary } \\
\text { school }\end{array}$} \\
\hline $\begin{array}{l}\text { Secondary } \\
\text { and } \\
\text { above(ref) }\end{array}$ & 2.839 & 0.009 & 0.520 & 1.354 & 1.862 & 0.002 & 0.167 & 0.659 \\
\hline \multicolumn{9}{|l|}{$\begin{array}{l}\text { How did you } \\
\text { find a job }\end{array}$} \\
\hline $\begin{array}{l}\text { Someone } \\
\text { found it } \\
\text { for me }\end{array}$ & 2.352 & 0.001 & 1.412 & 3.918 & 2.412 & 0.001 & 1.433 & 2.523 \\
\hline $\begin{array}{l}\text { I found it } \\
\text { myself(ref) }\end{array}$ & & & & & & & & \\
\hline \multicolumn{9}{|l|}{$\begin{array}{l}\text { Type of family } \\
\text { where he/she } \\
\text { live }\end{array}$} \\
\hline Extended & 4.421 & 0.007 & 1.514 & 12.913 & 4.672 & 0.002 & 0.0709 & 0.719 \\
\hline Nuclear & & & & & & & & \\
\hline $\begin{array}{l}\text { Single } \\
\text { parent } \\
\text { (ref) }\end{array}$ & 3.921 & 0.01 & 1.342 & 11.459 & 4.031 & 0.023 & 0.101 & 0.902 \\
\hline
\end{tabular}

\section{Discussion}

The aim of the study was to assess the risk factors associated with sexual abuse against house girls and house boys in Singida municipality, central zone-Tanzania.

One of the vital aspects of protecting house girls and house boys from sexual abuse, suspected cases must be reported immediately. Because most of house girls and house boys do not disclosure the information, the reporting of suspected cases by external people is very fatal. Only when a case is reported can be prosecuted and imprisoned by doing such kind of ashamed things(8).

Based on the results, it found that house girls and house boys who have high level of education were very knowledgeable about risk factors on sexual abuse, therefore the government and other NGOs they have a great job to educate both house girls and house boys in the societies so as to reduce the incidence of abuse. Not only that, the study showed that the type of family where house girls or house boys live they contribute much in causing these people to be abused especially extended and single parent family. 
Moreover, those people who used find the means of job to house girls or house boys should be prohibited restricted to do so, because it show that $43.2 \%$ of the house girls or house boys are engaged on this kind of work is due to this people. Lastly, low economic status of most family at Singida municipal cause the adolescents to move into such kind of work, were the statistics showed that $48.6 \%$ of the respondents responded that low economic status of the family causes most adolescents to engage in house girls and house boys(9). But most of study done by different researchers were about sexual abuse on children, women and men and no research done on factors association between knowledge on risk factors and sexual abuse on house girls and house boys.

\section{Limitations Of The Study}

The mother house or father house were very angry when interviewing the one among of his/her worker because of fearing that he/she could provide the information about his/her boss. Not only that but also the time which was used to collect data was a rainy season this was also a hindrance for me and not forgetting the distance from one house to another was a problem. Therefore, in order to have good response privacy and confidentiality was maintained and the information was not disclosed to the third part.

\section{Conclusion}

The overall result is that many house girls had inadequate knowledge 34(53.1\%) compared to house boys $50(48.9 \%)$ among 252 participants in Singida municipality on risk factors associated with sexual abuse and it discovered that the influencing factors were education level, means of getting a job and the type of family. Therefore, this high number of house girls with inadequate knowledge is caused by inadequate education provided by NGOs and government about sexual abuse among house girls and house boys in Singida municipality.

\section{List Of Abbreviations}

CDC- Center and disease Control.

GBV-Gender Based Violence

CSA-Child Sexual Abuse

SGBV-Sexual and Gender based violence

UNICEF-United Nations Children's Fund

WHO-World Health Organization

\section{Declarations}

\section{Ethical approve and consent to participate}

The ethical clearance approval was obtained from the University of Dodoma with high contribution from the Research review committee. Then the overall consent to participate to the community was provided by the Singida municipal. Also both written and oral informed consent to the house girls and house boys were given before starting data collection so as to ensure confidentiality and autonomy of the respondents, no names of the respondents were involved in the questionnaires. 


\section{Consent for publication}

Not applicable

\section{Availability of data and materials}

The datasets used for the current study are available from the corresponding author on reasonable request.

\section{Competing interest}

The authors declare that they have no competing interests

\section{Funding}

The authors depict that there is no financial support for this manual script to be published.

\section{Author's contributions}

F E established the study and contributed much to study design and data collection. D. P contributed on data analysis. W. M and A. J contributed on close supervision and guiding the conceptualization of the study, and review of the study design, data analysis, and manuscript development.

\section{Acknowledgement}

Basically, I stood exceptionally grateful to our God who gave me vitality, life, and power to accomplish this work. I am thankful to the people who gave me a proficient help during composing my research report. In a wonderful manner, I am stretching out my earnest appreciation to my supervisors Dr. Angelina A. Joho, Dr. Fabiola Moshi and Walter C. Milanzi for their persistent help, backing and direction all through procedure of instructing and building up this study report. Likewise, I genuinely thank my kindred Dedius E. Peter for his time and assistance and guidance both empowering me to achieve my work

\section{References}

1. Child W, Pds W, Reporter M. Definition of Sexual Abuse. 2016;(2016):1-3.

2. CDC. Preventing Sexual Violence. 2019;

3. CDC. National Intimate Partner and Sexual Violence Survey 2010 Summary Report. 2010; (2011).

4. WHO. Understanding and addressing violence against women Sexual violence. 2010;

5. Radford L, Allnock D, Hynes P. Preventing and Responding to Child Sexual Abuse and Exploitation: Evidence review. 2016;(2016).

6. Meinck F, Cluver L, Loening-voysey H, Bray R, Casale M, Sherr L, et al. Disclosure of physical , emotional and sexual child abuse, help-seeking and access to abuse response services in two South African Provinces. Psychol Health Med. 2017;8506(January):1-13.

7. Israel GD. Determining Sample Size 1. 1992;(November):1-5.

8. Wiley. Risk and protective factors for physical and emotional abuse victimisation amongst vulnerable children in South Africa. Child Abus Rev. 2015;1-18.

9. Rule dm. Factors that Influence the reporting of child Sexual abuse versity e to w n ve rs ity e to w. 2017; 